\title{
High Pressure Source/Cryostat Relief Solutions
}

DO Engineering Note 3740.512-EN-1 15

S. J. Wintercorn, $8 / 13 / 87$

edited and up dated by.

G. T. Mulholland, 9/23/87

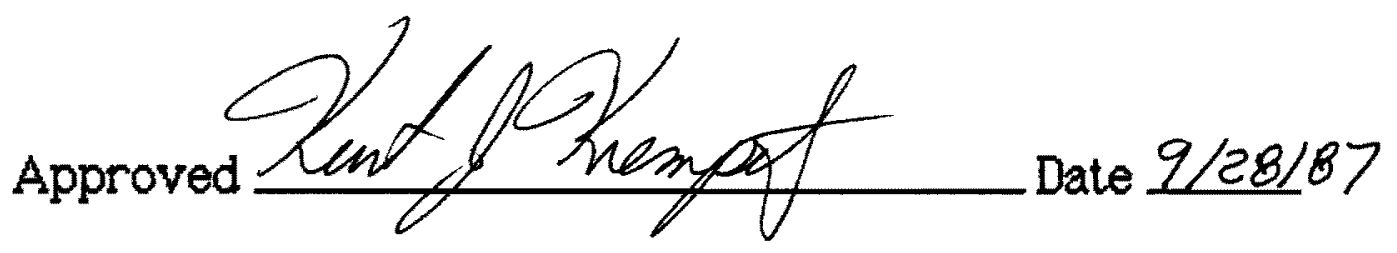




\section{High Pressure Source/ Cryostat Relief Solutions}

\section{Introduction}

This report addresses solutions to the potential problem of cryostat overpressurization by the nominal 65 psi MWAP LAr source dewar. Uncontrolled (by reason of failure) filling of a 15 psi MWAP cryostat by the LAr fill line could cause overpressurization by overwhelming the provided cryostat relief system. Three levels of protection against overpressurization by the source dewar are mentioned in this report; the reduced (operational) relief pressure, the source pressure regulator, and the LAr dewar cooling loop (see lig. 1). Only the first of these is recognized by the ASME code as sufficient protection. the others provide operational convenience and avoid the loss of detector fluid.

Flow limiting device solutions are not considered because of the conflicting requirement to empty and fill the cryostats rapidly (within one eight hour shift), e.g. the movement of the cryostat from the assembly hall to the collision hall, or the inverse operation.

\section{Solutions}

The controls solution limits the liquid fill line source pressure with a pressure regulator. There is a problem with this solution: according to the ASME Code, Section VIII, Division 1, Par. UG-125(h), "Note: Pressure reducing valves and similar mechanical or electrical control instruments, except for pilot operated valves as permitted in UG-126(b), are not considered as sufficiently positive in action to prevent excess pressures from being developed." The LAr dewar pressure under filling conditions will be limited to solve this problem. The dewar pressure will be limited by placing a LP "operate" relief valve/rupture disc combination on one side of the dewar dual relief system (see fig. 2). The dewar relief selector valve will be locked, and verified locked, in the "operate" position as a part of the fill procedure, and prior to the jumper connection. The operating relief valve will be set to $16 \mathrm{psig}$ and the rupture disc to $22 \mathrm{psig}$. The attached calculations demonstrate the resulting flow limit is within the cryostat relief capacity. A third level of dewar source pressure limitation is the LAr dewar, $\mathrm{LN}_{2}$ cooling loop. The Back pressure regulator and cooling loop can. of course, malfunction to the default pressure limit of the "operate" relief.

\section{Conclusion}

Cryostat overpressurization is precluded by the proper implementation of the safety precautions listed in this report. That work will be initiated immediately. See DO Engineering Note ${ }^{*} 111$ for the sizing of this relief. 
Three Levels of Protection Against Cryostat Overpressure by "Infinite" Source

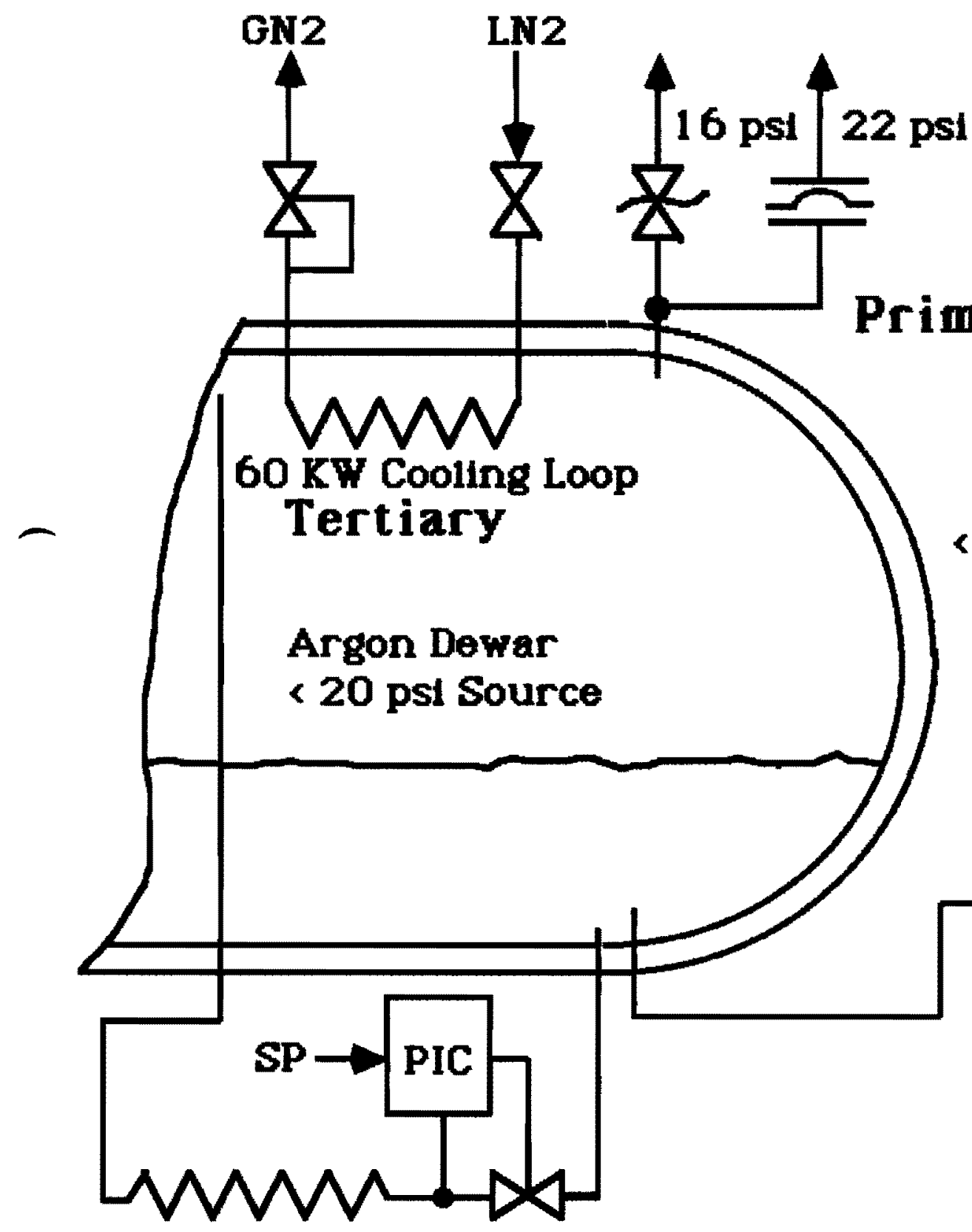

< 16 psi Regulator

Pressure Building Loop 


\section{Modification to the LAr Dewar Vent To Solve Fill Failure Mode of Cryostat}

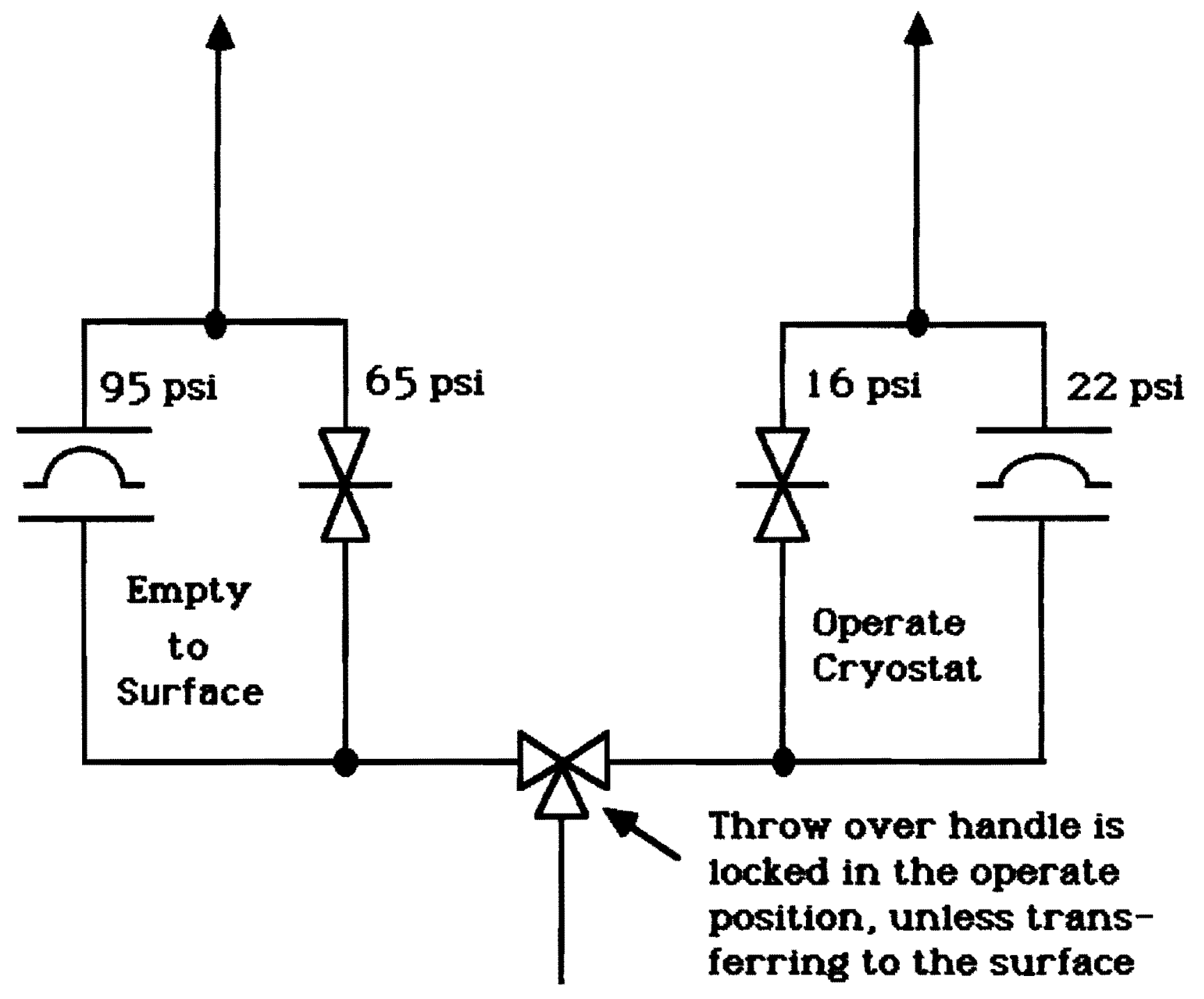

To LAr

Dewar 